\title{
Simultaneous Detection of Catechol and Hydroquinone by Gold Nanorods/Poly( $L$-cysteine) Modified Electrode
}

\author{
Keying zhang*, Deshun Cheng, Lei Yang, Ziqiang Zhang, Xiaoling Li, Na zhang* \\ Anhui Key Laboratory of Spin Electron and Nanomaterials; School of Chemistry and Chemical \\ Engineering, Suzhou University, Suzhou, Anhui 234000, China. \\ *E-mail: zhangky1983@163.com ; szxyzn@163.com
}

doi: $10.20964 / 2020.08 .68$

Received: 15 April 2020 / Accepted: 11 June 2020 / Published: 10 July 2020

Herein, a poly( $L$-cysteine) modified glassy carbon electrode was prepared by electropolymerization. Gold nanorods were assembled onto the surface of the poly( $L$-cysteine) modified electrode surface via $\mathrm{Au}-\mathrm{S}$ bonds. Scanning electron microscope was used to characterize gold nanorods. The final electrode was used for the detection of catechol and hydroquinone. The results showed that this modified electrode exhibited obvious electrocatalytic effect on catechol and hydroquinone. Differential pulse voltammetry was used to detect catechol and hydroquinone in $0.1 \mathrm{~mol} / \mathrm{L}$ phosphate buffer solution $(\mathrm{pH}=7.0)$. The detection limit was $2.6 \times 10^{-7} \mathrm{~mol} / \mathrm{L}$ and $1.2 \times 10^{-7} \mathrm{~mol} / \mathrm{L}$, respectively. In addition, the proposed electrode had good stability and reproducibility, and could be used for detecting catechol and hydroquinone in samples.

Keywords: Modified electrode, Gold nanorods, poly(L-cysteine), Catechol, Hydroquinone

\section{FULL TEXT}

(C) 2020 The Authors. Published by ESG (www.electrochemsci.org). This article is an open access article distributed under the terms and conditions of the Creative Commons Attribution license (http://creativecommons.org/licenses/by/4.0/). 